\title{
Faktor-Faktor yang Berhubungan dengan Kepatuhan Berobat J alan Pasien Diabetes Mellitus Tipe II
}

\author{
Lenny $^{1}$, Fridalina ${ }^{2}$ \\ Program Studi IImu Kesehatan Masyarakat, Universitas Sari Mutiara Indonesia \\ J. Kapten Muslim No 79, Medan 20123 \\ e-mail : ${ }^{1}$ felixfarrel@gmail.com, 2fridalina_tarigan@yahoo.com
}

\begin{abstract}
Abstrak
Penyakit DM merupakan ancaman kesehatan masyarakat secara global, dimana sekitar $90 \%$ dari semua pasien yang menderita DM di seluruh dunia adalah DM tipe II. Hasil survei awal yang dilakukan di RSU Kabanjahe mengenai data pasien yang menderita DM Tipe Ilpada tahun 2016 penderita DM tipe II sebanyak 426 orang, dan melakukan berobat jalan sebanyak 382 orang. Tujuan penelitian ini adalah untuk mengetahui faktor-faktor yang berhubungan dengan kepatuhan berobat.Jenis penelitian adalah survei analitik dengan desain cross sectional. Populasi dalam penelitian ini adalah seluruh pasien DM tipe II di RSU Kabanjahe Januari - Desember 2016 sebanyak 382 orang, dengan jumlah sampel sebanyak 92 orang (accidental sampling). Analisis data menggunakan uji chi square. Hasil penelitian menunjukkan tidak terdapat hubungan pekerjaan $(p=0,741)$, lama menderita $(p=0,299)$, motivasi berobat $(p=0,333)$, keterjangkauan pelayanan kesehatan $(p=1,000)$, keikutsertaan askes $(p=0,5 \mid 5)$, dukungan keluarga $(p=0,254)$, peran tenaga kesehatan $(p=0,880)$ dengan kepatuhan berobat jalan. Namun pengetahuan $(p=033)$ berpengaruh signifikan dan merupakan faktor yang dominan berhubungan dengan kepatuhan berobat jalan pasien DM II di RSU Kabanjahe 2017 dengan nilai Exp $B=0,330$. Dengan demikian diharapkan bagi masyarakat yang menderita penyakit DM Tipe II agar memeriksakan diri dan melakukan pengobatan secara teratur untuk meningkatkan kesehatannya dan peran petugas dan pihak RSU Kabanjahe dapat mengajak masyarakat melalui upaya promotif, preventif, kuratif dan rehabilitatif agar dapat meningkatkan kualitas hidup pasien, terutama dalam upaya peningkatan kualitas hidup masyarakat.
\end{abstract}

Kata kunci : Determinan, Kepatuhan Berobat, DM Tipe II

\begin{abstract}
DM (Diabetes Mellitus) is globally a health threat for people in which $90 \%$ of DM patients throughout the world sufferfrom DM Type II. The results of the prelimary survey at RSU Kabanjahe, in 2016,revealed that were 426 DM Type II patients, and 382 of them were outpatients. The objective of the research was to find out some factors which were correlation with the compliance of getting medication. The research used analytical survey method with cross sectional design. The population was 382 DM Type II patients at RSU Kabanjahe from January to December 2016, and 92 of them were used as the samples, taken by using accidental sampling technique. The data were analyzed by using chi square test. The result of the research showed that there was correlation of occupation $(p=0,74 I)$, duration of ilness $(p=0,299)$, motivation to get medication $(p=0,333)$, health care affordability $(p=1,000)$, askes participation $(p=0,515)$, family support $(p=$ $0,254)$, and the role of health care providers $(p=0.880)$ with compliance with being outpatients. However, knowledge had significant correlation and the most dominant correlation with compliance with being DM Type II outpatientsat RSU Kabanjahe, in 2017, at Exp $B=0,330$. It is recommended that those who suffer from DM Type II have their illness examined and do their medication regularly in order to improve their health. Health care providers and the hospital management ask people to participation in promoted, curative, and rehabilitative actions in order to increase patients and the people's life quality.
\end{abstract}

Keywords : Determinant, Compliance with Getting Medication, DM Type II 


\section{Pendahuluan}

Diabetes Mellitus (DM) adalah penyakit degeneratif yang terus meningkat prevalensinya di seluruh dunia. Data dari studi global menunjukkan bahwa jumlah penderita DM pada tahun 2013 telah mencapai 382 juta orang. Jika tidak ada tindakan yang dilakukan, maka jumlah ini diperkirakan akan meningkat menjadi 592 juta pada tahun 2035. Data dari studi global juga memperkirakan bahwa sebanyak 175 juta orang tidak menyadari bahwa mereka menghidap DM. Sebesar $80 \%$ orang dengan DM tinggal di negara berpenghasilan rendah dan menengah. ${ }^{\circ}$

Penyakit (DM) merupakan ancaman kesehatan masyarakat global, dimana sekitar 90\% dari semua pasien yang menderita DM di seluruh dunia adalah DM tipe II (WHO, 2015). Angka insidensi dan prevalensi DM tipe II di dunia cenderung meningkat setiap tahun mencapai 1,5 juta orang pada tahun 2012 dan pada tahun 2014 prevalensi penderita DM diperkirakan mencapai $9 \%$ dari total populasi dunia. ${ }^{2}$ Asia menyumbang lebih dari $60 \%$ penderita DM di seluruh dunia. ${ }^{3}$

Prevalensi penderita DM di Indonesia menempati urutan ke 7 dunia dengan jumlah penderita sebanyak 12 juta jiwa dan diperkirakan akan meningkat menjadi 21,3 juta jiwa pada tahun 2030 . Pada tahun 2013 angka kejadian DM adalah 2.1\%. Angka tersebut lebih tinggi dibanding dengan tahun 2007 (1,1\%). ${ }^{4}$

DM dibagi menjadi empat yaitu, DM tipe I, DM tipe II, DM gestasional, dan DM tipe lain. Dari keempat tipe DM jumlah terbanyak terdiagnosis adalah DM tipe II. ${ }^{12}$ Penderita DM tipe II yang rawat jalan RSU Herna Medan setiap tahunnya meningkat, tahun 2010 urutan keenam dari sepuluh penyakit terbanyak, sedangkan ditahun 2011 urutan kelima dengan jumlah kasus mulai Januari s/d Desember 2011 sebanyak 102 kasus, dan ditahun 2012 tetap pada urutan kelima hanya saja jumlah kasusnya bertambah sebanyak 132 kasus. ${ }^{11}$ Dalam kasus yang sama di RSUP H. Adam Malik Medan tahun 2011 ditemukan rata- rata jumlah kunjungan rawat jalan per bulan penderita DM tipe II sebanyak 36 penderita. Jumlah kunjungan ini meningkat di tahun 2012 hingga mencapai rata-rata 54 penderita per bulan.Hal ini menunjukan lonjakan peningkatan penderita DM tipe II dari tahun ke tahun. ${ }^{5}$

Hasil Riset Kesehatan Dasar khusus Provinsi Sumatera Utara tahun 2013, prevalensi DM tertinggi di Deli Serdang 2,9 \%, dan terendah di Mandailing Natal 0.3\%, sedangkan untuk daerah Karo berada pada $1,9 \%{ }^{6}$

Berdasarkan dari observasi survei awal yang peneliti lakukan dari RSU Kabanjahe data pasien yang menderita DM Tipe II pada tahun 2015 sebanyak 318 orang, dan yang melakukan berobat jalan sebanyak 296 orang. Sedangkan pada tahun 2016 penderita DM tipe II sebanyak 426 orang, dan melakukan berobat jalan sebanyak 382 orang.

Dari hasil data yang diperoleh terlihat bahwasanya penderita DM meningkat dari tahun 2015 sampai dengan 2016, sementara kunjungan pasien yang datang untuk berobat jalan menurun pada tahun 2015 dan 2016. Berdasarkan fenomena tersebut, maka penulis tertarik untuk melakukan penelitian tentang faktorfaktor yang berhubungan dengan kepatuhan berobat jalan pasien Dibates Mellitus tipe II di RSU Kabanjahe Tahun 2017.

\section{Metode}

Jenis penelitian adalah survei analitik atau explanatory (penjelasan) dengan desain cross sectional. Populasi dalam penelitian ini adalah seluruh pasien DM tipe II di RSU. Sampel dalam penelitian ini adalah sebagian dari populasi sebesar 92 orang. Dalam penelitian ini pengambilan sampel ditentukan dengan menggunakan accidental sampling, yaitu teknik pengambilan sampel yang dilakukan terhadap responden yang secara kebetulan ditemui pada tempat penelitian ketika observasi sedang berlangsung. 
Analisis Univariat

Tabel 1. Analisis Univariat

\begin{tabular}{llcc}
\hline \multicolumn{1}{c}{ Variabel } & \multicolumn{1}{c}{ Kategori } & n & \% \\
\hline Status Pekerjaan & Tidak Bekerja & 11 & 12,0 \\
& Bekerja & 81 & 88,0 \\
Lama Menderita & $>5$ tahun & 33 & 35,9 \\
& $\leq 5$ tahun & 59 & 64,1 \\
Pengetahuan & Kurang baik & 56 & 60,9 \\
& Baik & 36 & 39,1 \\
Motivasi Berobat & Kurang baik & 30 & 32,6 \\
& Baik & 62 & 67,4 \\
Keterjangkauan & Tidak & 41 & 44,6 \\
pelayanan & Terjangkau & & \\
kesehatan & Terjangkau & 51 & 55,4 \\
Keikutsertaan & Tidak ikut & 30 & 32,6 \\
Askes & askes & & \\
& Ikut askes & 62 & 67.4 \\
Dukungan & Tidak & 33 & 35,9 \\
Keluarga & mendukung & & \\
& Mendukung & 59 & 64,1 \\
Peran Tenaga & Tidak & 51 & 55,4 \\
Kesehatan & berperan & & \\
Kepatuhan & Berperan & 41 & 44,6 \\
berobat & Tidak patuh & 58 & 63,0 \\
\hline & Patuh & 34 & 37,0 \\
\hline
\end{tabular}

Berdasarkan status pekerjaan diketahui responden dengan kategori tidak bekerja yaitu 11 orang (12,0\%), dan yang bekerja 81 orang $(88,0 \%)$. Responden yang menderita diabetes $>5$ tahun sebanyak 33 orang $(35,9 \%)$ dan $\leq 5$ tahun sebanyak 59 orang $(64,1 \%)$. Pengetahuan responden dengan kategori kurang baik yaitu 56 (60,9\%) dan pengetahuan yang baik 36 (39,1\%). Pada umumnya responden memiliki motivasi berobat yang baik sebanyak 62 orang $(67,4 \%)$ dan responden yang memiliki motivasi yang kurang baik sebanyak 30 (32,6\%). Berdasarkan keterjangkauan pelayanan kesehatan, responden menyatakan terjangkau sebanyak $51 \quad$ (55,4\%), sedangkan yang tidak terjangkau 41 (44,6\%). Responden yang menyatakan keikutsertaan askes sebanyak baik 62 orang $(67,4 \%)$ dan yang menyatakan tidak ikut askes sebanyak 30 orang (32,6\%). Penderita DM yang mendapat dukungan keluarga sebanyak 59 orang $(64,1 \%)$ dan yang tidak sebanyak 33 orang (35,9\%). Tidak adanya peran tenaga kesehatan dalam kepatuhan berobat sebanyak 51 orang $(55,4 \%)$ dan yang berperan sebanyak 41 orang $(44,6 \%)$. Sehingga diperoleh penderita DM yang tidak patuh sebanyak 58 orang $(63,0 \%)$ dan yang patuh sebanyak 34 orang $(37,0 \%)$.

\section{Analisis Bivariat}

Tabel 2. Hasil Analisis Bivariat

\begin{tabular}{|c|c|c|c|c|c|c|}
\hline \multirow{3}{*}{ Variabel } & \multirow{3}{*}{ Kategori } & \multicolumn{4}{|c|}{ Kepatuhan Berobat } & \multirow{3}{*}{$P$ value } \\
\hline & & \multicolumn{2}{|c|}{ Tidak Patuh } & \multicolumn{2}{|c|}{ Patuh } & \\
\hline & & $\mathbf{n}$ & $\%$ & $\mathbf{n}$ & $\%$ & \\
\hline \multirow[t]{2}{*}{ Status Pekerjaan } & Tidak Bekerja & 8 & 72,7 & 3 & 27,3 & \multirow{2}{*}{0,741} \\
\hline & Bekerja & 50 & 61,7 & 31 & 38,3 & \\
\hline \multirow[t]{2}{*}{ Lama menderita } & $>5$ & 18 & 54,5 & 15 & 45,5 & \multirow{2}{*}{0,299} \\
\hline & $\leq 5$ & 40 & 67,8 & 19 & 32,2 & \\
\hline \multirow[t]{2}{*}{ Pengetahuan } & Kurang baik & 30 & 53,6 & 26 & 46,4 & \multirow{2}{*}{0,033} \\
\hline & Baik & 28 & 77,8 & 8 & 22,2 & \\
\hline \multirow[t]{2}{*}{ Motivasi Berobat } & Kurang baik & 24 & 80,0 & 6 & 20,0 & \multirow{2}{*}{0,035} \\
\hline & Baik & 34 & 54,8 & 28 & 45,2 & \\
\hline \multirow{4}{*}{$\begin{array}{l}\text { Keterjangkauan pelayanan } \\
\text { kesehatan } \\
\text { Keikutsertaan Askes }\end{array}$} & Tidak Terjangkau & 30 & 73,2 & 11 & 26,8 & \multirow{2}{*}{0,112} \\
\hline & Terjangkau & 28 & 54,9 & 23 & 45,1 & \\
\hline & Tidak ikut askes & 17 & 56,7 & 13 & 43,3 & \multirow{2}{*}{0,515} \\
\hline & Ikut askes & 41 & 66,1 & 21 & 33,9 & \\
\hline \multirow[t]{2}{*}{ DukunganKeluarga } & Tidak Mendukung & 29 & 87,9 & 4 & 12,1 & \multirow{2}{*}{0,001} \\
\hline & Mendukung & 29 & 49,2 & 30 & 50,8 & \\
\hline \multirow{2}{*}{ Peran Tenaga Kesehatan } & Tidak berperan & 33 & 64,7 & 18 & 35,3 & \multirow{2}{*}{0,880} \\
\hline & Berperan & 25 & 61,0 & 16 & 39,0 & \\
\hline
\end{tabular}


Hasil penelitian tentang hasil uji statistik dengan uji Chi-Square menunjukkan tidak terdapat hubungan yang signifikan antara status pekerjaan dengan kepatuhan berobat, nilai probabilitas $(\mathrm{p})=0,741>0,05$. Hasil uji statistik dengan uji Chi-Square menunjukkan tidak terdapat hubungan yang signifikan antara lama menderita dengan kepatuhan berobat, nilai probabilitas $(p)=0,299>0,05$. Hasil uji statistik dengan uji Chi-Square menunjukkan ada hubungan yang signifikan antara pengetahuan dengan kepatuhan berobat, nilai probabilitas $(\mathrm{p})=$ $0,033<0,05$. Hasil uji statistik dengan uji Chi-Square menunjukkan terdapat hubungan yang signifikan antara motivasi berobat dengan kepatuhan berobat, nilai probabilitas $(p)=0,035<0,05$. Hasil uji statistik dengan uji Chi-Square menunjukkan tidak terdapat hubungan yang signifikan antara keterjangkauan pelayanan kesehatan dengan kepatuhan berobat, nilai probabilitas $(\mathrm{p})=0,112>$ 0,05. Hasil uji statistik dengan uji ChiSquare menunjukkan tidak terdapat hubungan yang signifikan antara keikutsertaan askes dengan kepatuhan berobat, dengan nilai probabilitas $(\mathrm{p})=$ $0,515>0,05$. Hasil uji statistik dengan uji Chi-Square menunjukkan terdapat hubungan yang signifikan antara dukungan keluarga dengan kepatuhan berobat, dengan nilai probabilitas $(\mathrm{p})=0,001<$ 0,05 . Hasil uji statistik dengan uji ChiSquare menunjukkan tidak ada hubungan yang signifikan antara peran tenaga kesehatan dengan kepatuhan berobat, dengan nilai probabilitas $(\mathrm{p})=0,880>$ 0,05 .

\section{Analisis Multivariat}

Hasil akhir regresi logistik menunjukkan bahwa variabel pengetahuan merupakan variabel yang dominan berhubungan dengan kepatuhan berobat jalan. Dengan hasil OR $=0,330$, yang berarti bahwa pengetahuan yang baik penderita DM Tipe II mengenai Diabetes Mellitus akan meningkatkan kepatuhan berobat jalan pasien sebanyak 0,33 kali lebih besar dibandingkan dengan pasien yang kurang memiliki pengetahuan tentang Diabetes Mellitus.

Tabel 3 Hasil Seleksi Akhir Variabel

\begin{tabular}{lrrrrr}
\hline \multirow{2}{*}{ Variabel } & \multirow{2}{*}{ B } & \multirow{2}{*}{ Sig } & \multirow{2}{*}{ Exp B } & \multicolumn{2}{c}{ 95\%CI } \\
\cline { 6 - 7 } & & & & Lower & Upper \\
\hline Pengetahuan & $-1,110$ &, 021 &, 330 &, 128 &, 848 \\
Constant &,- 143 &, 593 &, 867 & & \\
\hline
\end{tabular}

Pembahasan

Hubungan Status Pekerjaan Dengan Kepatuhan Berobat Jalan Pasien Diabetes Mellitus tipe II di RSU Kabanjahe Tahun 2017

Berdasarkan hasil penelitian tentang hubungan status pekerjaan dengan kepatuhan berobat jalan menunjukkan bahwa dari 81 orang yang bekerja, terdapat 50 orang $(61,7 \%)$ yang tidak patuh terhadap kepatuhan berobatnya. Dan hanya 31 orang $(38,3 \%)$ yang patuh terhadap kepatuhan berobatnya. Sedangkan dari 11 orang yang tidak bekerja terdapat
8 orang (72,7\%) yang tidak patuh. Dan hanya 3 orang $(27,3 \%)$ yang patuh terhadap kepatuhan berobatnya. Hasil uji statistik dengan uji Chi-Square menunjukkan tidak terdapat hubungan yang signifikan antara status pekerjaan dengan kepatuhan berobat, nilai probabilitas $(p)=0,741>0,05$. Tidak ada hubungan antara pekerjaan dengan kepatuhan pengobatan pasien DM Tipe II dengan nilai $p=0,908$. $^{7}$

Berdasarkan penelitian dilapangan, ditemukan bahwa responden yang tidak bekerja maupun yang bekerja tetap patuh 
menjalani pengobatan. Sehingga dapat disimpulkan bahwa tidak ada perbedaan kepatuhan berobat penderita DM tipe II pada responden yang bekerja maupun yang tidak bekerja. Tidak adanya perbedaan ini dikarenakan sebagian besar responden yang bekerja berada disektor non-formal yang tidak ditentukan batasan waktu kerjanya, sehingga meskipun responden bekerja namun tetap memiliki kesempatan dan ketersediaan waktu yang sama dengan responden yang tidak bekerja untuk melakukan pengobatan DM Tipe II yang dijalaninya.

\section{Hubungan Lama Menderita Dengan Kepatuhan Berobat Jalan Pasien Diabetes Mellitus tipe II di RSU Kabanjahe Tahun 2017}

Berdasarkan hasil penelitian
hubungan lama menderita dengan kepatuhan berobat jalan menunjukkan bahwa dari 59 orang yang lama menderitanya $>5$ terdapat 40 orang (67,8\%), yang tidak patuh. Dan yang patuh hanya 19 orang $(32,2 \%)$. Sedangkan dari 33 yang lama menderitanya $<=5$ terdapat 18 orang $(54,5 \%)$ yang tidak patuh. Dan hanya 15 orang (45,5\%) yang patuh terhadap kepatuhan berobatnya. Hasil uji statistik dengan uji Chi-Square menunjukkan tidak terdapat hubungan yang signifikan antara lama menderita dengan kepatuhan berobat, nilai probabilitas $(p)=0,299>0,05$.

Lama menderita DM Tipe II tidak berhubungan dengan kepatuhan dalam berobat jalan DM Tipe II. Menurut analisis Suhadi, lama menderita DM Tipe II berkaitan dengan lamanya melakukan pengobatan DM Tipe II, sehingga lama menderita DM Tipe II bukan menjadi faktor yang mempengaruhi kepatuhan dalam berobat jalan.

Tingkat kepatuhan penderita DM untuk berobat dan kontrol cukup rendah. Semakin lama seseorang menderita DM maka tingkat kepatuhanya makin rendah, hal ini disebabkan kebanyakan penderita akan merasa bosan untuk berobat. ${ }^{8}$

\section{Hubungan Pengetahuan Dengan \\ Kepatuhan Berobat Jalan Pasien Diabetes Mellitus Tipe II di RSU Kabanjahe Tahun 2017. \\ Berdasarkan hasil penelitian} hubungan pengetahuan pasien dengan kepatuhan berobat jalan menunjukkan bahwa dari 56 orang yang pengetahuannya kurang baikterdapat 30 orang $(53,6 \%)$ tidak patuh dan hanya 26 orang $(48,4 \%)$ saja yang patuh terhadap kepatuhan berobatnya. Sedangkan dari 36 orang yang pengetahuannya baik terdapat 28 orang (77,8\%) yang tidak patuh terhadap kepatuhan berobatnya. Dan hanya 8 orang (22,2\%) yang pengetahuannya baik dan patuh kepada kepatuhan berobatnya. Hasil uji statistik dengan uji Chi-Square menunjukkan ada hubungan yang signifikan antara pengetahuan dengan kepatuhan berobat, nilai probabilitas $(\mathrm{p})=$ $0,033<0,05$.

Pengetahuan dapat diartikan sebagai kumpulan informasi yang dipahami, diperoleh dari proses belajar selama hidup dan dapat dipergunakan sewaktu-waktu sebagai alat penyesuaian diri, baik terhadap diri sendiri maupun lingkungan. Pengetahuan tentang suatu objek dapat diperoleh dari pengalaman guru, orang tua, teman, buku dan media massa. ${ }^{2}$ Dapat disimpulkan dari teori tersebut bahwa pengetahuan penderita DM dapat menjadi guru yang baik bagi dirinya, dengan pengetahuan yang dimiliki akan mempengaruhi kepatuhan penderita DM tersebut dalam menjalani pengobatan. Penderita yang mempunyai pengetahuan tinggi cenderung lebih patuh berobat daripada penderita yang berpengetahuan rendah. $^{9}$

Sebaliknya yaitu tidak terdapat hubungan antara tingkat pengetahuan pasien DM Tipe II terhadap kepatuhan untuk berobat. Hal ini disebabkan karena responden merasa DM merupakan penyakit yang susah disembuhkan sehingga tidak banyak manfaat untuk berobat lebih lama. ${ }^{7}$ 
Hubungan Motivasi Berobat Dengan Kepatuhan Berobat Jalan Pasien DM Tipe II di RSU Kabanjahe Tahun 2017.

Berdasarkan hasil penelitian hubungan motivasi berobat dengan kepatuhan berobat jalan menunjukkan bahwa dari 62 orang yang motivasi berobatnya baikterdapat 34 orang $(54,8 \%)$ yang tidak patuh terhadap kepatuhan berobatnya. Dan hanya 28 orang (45,2\%) yang motivasi berobatnya baik dan patuh terhadap kepatuhan berobatnya.Sedangkan dari 30 orang yang motivasi berobatnya kurang baik, terdapat 24 orang (80,0\%) yang tidak patuh terhadap kepatuhan berobatnya. Dan hanya 6 orang (20,8\%) yang kurang baik tetapi patuh terhadap kepatuhan berobatnya. Hasil uji statistik dengan uji Chi-Square menunjukkan terdapat hubungan yang signifikan antara motivasi berobat dengan kepatuhan berobat, nilai probabilitas $(\mathrm{p})=0,0,35<$ 0,05 .

Motivasi berarti dorongan dari dalam diri manusia untuk bertindak atau berperilaku (reasoning) seseorang untuk bertindak dalam rangka memenuhi kebutuhan hidupnya.Pengertian motivasi tidak terlepas dari kata kebutuhan atau keinginan.Motivasi pada dasarnya merupakan interaksi seseorang dengan situasi tertentu yang dihadapinya. ${ }^{10}$ Sehingga dapat disimpulkan bahwa motivasi yang tinggi membuat seseorang untuk lebih patuh dalam menjalani pengobatan. Tingginya motivasi dapat dipengaruhi oleh dorongan dari orang lain dalam hal ini adalah keluarga, karena penderita DM Tipe II dengam motivasi tinggi adalah mereka yang menerima dukungan yang baik dari keluarganya. Motivasi yang tinggi terbentuk karena adanya hubungan antara dorongan, tujuan dan kebutuhan untuk sembuh. Dengan adanya kebutuhan untuk sembuh, maka penderita DM Tipe II akan terdorong untuk patuh dalam menjalani pengobatan secara rutin.

Hubungan motivasi dengan kepatuhan berobat pasien DM Tipe II.
Motivasi berpengaruh signifikan terhadap kepatuhan berobat pasien DM Tipe II dan pengetahuan merupakan variabel yang paling berpengaruh $(p=0,063<0,005){ }^{11}$

$\begin{aligned} & \text { Hubungan } \\ & \text { Pelayanan } \\ & \text { Kesehatan }\end{aligned}$
$\begin{aligned} & \text { Kepatuhan Berobat Jalan } \\ & \text { Diabetes Mellitus Tipe II di RSU } \\ & \text { Kabanjahe Tahun 2017 }\end{aligned}$

\begin{tabular}{ccc}
\multicolumn{2}{c}{ Berdasarkan hasil penelitian } \\
hubungan keterjangkauan
\end{tabular} kesehatan dengan kepatuhan berobat jalan menunjukkan bahwa dari 51 orang yang terjangkau pelayanan kesehatannya, terdapat 28 orang $(54,9 \%)$ yang tidak patuh terhadap kepatuhan berobatnya. Dan hanya 23 orang $(45,1 \%)$ yang terjangkau pelayanan kesehatannya dan patuh terhadap kepatuhan berobatnya. Dari 41 orang yang tidak terjangkau pelayanan kesehatannya terdapat 30 orang $(73,2 \%)$ yang tidak patuh terhadap kepatuhan berobatnya. Dan 11 orang (25,8\%) yang tidak terjangkau pelayanan kesehatannya tetapi patuh terhadap kepatuhan berobatnya. Hasil uji statistik dengan uji Chi-Square menunjukkan tidak terdapat hubungan yang signifikan antara keterjangkauan pelayanan kesehatan dengan kepatuhan berobat, nilai probabilitas $(\mathrm{p})=0,112>0,05$.

Keterjangkauan akses ke pelayanan kesehatan adalah mudah atau sulitnya seseorang untuk mencapai tempat pelayanan kesehatan. Salah satu faktor yang mempengaruhi kepatuhan berobat adalah faktor yang mendukung (enabling factor), yang terdiri atas tersedianya fasilitas kesehatan, kemudahan untuk menjangkau sarana kesehatan serta keadaan sosial ekonomi dan budaya.Rendahnya penggunaan fasilitas kesehatan seperti puskesmas, rumah sakit dan sebagainya, seringkali kesalahan atau penyebabnya dilemparkan pada faktor akses ke pelayanan kesehatan (baik itu akses tempuh dan jarak ke fasilitas kesehatan). ${ }^{12}$ Keterjangkauan akses yang dimaksud dalam penelitian ini dilihat dari 
segi jarak, waktu tempuh dan kemudahan transportasi untuk mencapai pelayanan kesehatan. Semakin jauh jarak rumah pasien dari tempat pelayanan kesehatan dan sulitnya transportasi maka, akan berhubungan dengan kepatuhan berobat. Sehingga dapat dikatakan orang yang tidak mudah menjangkau tempat pelayanan kesehatan justru lebih patuh dibandingkan dengan orang yang mudah menjangkau tempat pelayanan kesehatan.

\section{Hubungan Keikutsertaan Asuransi Kesehatan Dengan Kepatuhan Berobat Jalan Pasien Diabetes Mellitus Tipe II di RSU Kabanjahe Tahun 2017.}

Berdasarkan hasil penelitian hubungan keikutsertaan askes dengan kepatuhan berobat jalan menunjukkan bahwa dari 62 orang yang yang mengatakan keikut sertaan askes, 41 orang (66,1\%) yang tidak patuh terhadap kepatuhan berobatnya. Dan hanya 21 orang (33,9\%) yang mengatakan keikutikut sertaan askes dan patuh terhadap kepatuhan berobatnya. Sedangkan dari 30 orang yang mengatakan tidak ikut askes, terdapat 17 orang $(56,7 \%)$ yang tidak patuh terhadap kepatuhan berobatnya. Dan 13 (43,3\%) yang mengatakan tidak ikut askes tetapi patuh terhadap kepatuhan berobatnya. Hasil uji statistik dengan uji Chi-Square menunjukkan tidak terdapat hubungan yang signifikan antara keikutsertaan askes kesehatan dengan kepatuhan berobat, dengannilai probabilitas $(p)=0,515>0,05$.

Asuransi kesehatan merupakan asuransi yang obyeknya adalah jiwa, tujuan asuransi kesehatan adalah memperalihkan risiko biaya sakit dari tertanggung (pemilik) kepada penanggung. Sehingga kewajiban penanggung adalah memberikan pelayanan (biaya) perawatan kesehatan kepada tertanggung apabila sakitKetersediaan atau keikutsertaan asuransi kesehatan berperan sebagai faktor kepatuhan berobat pasien, dengan adanya asuransi kesehatan didapatkan kemudahan dari segi pembiayaan sehingga lebih patuh dibandingkan dengan yang tidak memiliki asuransi kesehatan. ${ }^{11}$

\section{Hubungan Dukungan Keluarga Dengan Kepatuhan Berobat Jalan Pasien Diabetes Mellitus Tipe II di RSU Kabanjahe Tahun 2017.}

Berdasarkan hasil penelitian hubungan dukungan keluarga dengan kepatuhan berobat jalan menunjukkan bahwa dari 59 orang yang mendapatkan dukungan keluarga, terdapat 29 orang (49,2\%) yang tidak patuh terhadap kepatuhan berobatnya. Dan 30 orang (50,8\%) yang mendapatkan dukungan keluarga dan patuh terhadap kepatuhan berobatnya. Sedangkan dari 33 orang yang tidak mendapatkan dukungan keluarga, terdapat 29 orang $(87,9 \%)$ yang tidak patuh terhadap kepatuhan berobatnya. Dan 30 orang $(50,8 \%)$ yang tidak mendapatkan dukungan keluarga tetapi patuh terhadap kepatuhan berobatnya. Hasil uji statistik dengan uji Chi-Square menunjukkan tidak terdapat hubungan yang signifikan antara dukungan keluarga dengan kepatuhan berobat, nilai probabilitas $(\mathrm{p})=0,001<$ 0,05 .

Keluarga adalah unit terkecil masyarakat. Untuk mencapai perilaku sehat masyarakat, maka harus dimulai pada masing-masing tatanan keluarga.Dalam teori pendidikan dikatakan, bahwa keluarga adalah tempat persemaian manusia sebagai anggota masyarakat. Karena itu bila persemaian itu jelek maka jelas akan berpengaruh pada masyarakat. Agar masing-masing keluarga menjadi tempat yang kondusif untuk tempat tumbuhnya perilaku sehat bagi anak-anak sebagai calon anggota masyarakat, maka promosi sangat berperan. ${ }^{10}$ Dukungan keluarga merupakan sikap, tindakan dan penerimaan terhadap penderita yang sakit. Penderita DM sangat memerlukan dukungan sosial dari orang lain selama menjalani proses pengobatanya.

Hubungan Peran Tenaga Kesehatan Dengan Kepatuhan Berobat Jalan 


\section{Pasien Diabetes Mellitus Tipe II di RSU Kabanjahe Tahun 2017.}

Berdasarkan hasil penelitian hubungan peran tenaga kesehatan dengan kepatuhan berobat jalan menunjukkan bahwa dari 51 orang tenaga kesehatan yang tidak berperan, terdapat 33 orang (64,7\%) yang tidak patuh terhadap kepatuhan berobatnya. Dan hanya 18 orang (35,3\%) yang patuh terhadap kepatuhan berobatnya. Sedangkan dari 41 orang tenaga kesehatan yang berperan, terdapat 25 orang pasien $(61,0 \%)$ yang tidak patuh terhadap kepatuhan berobatnya. Dan hanya 16 orang $(39,0 \%)$ orang pasien yang patuh terhadap kepatuhan berobatnya. Hasil uji statistik dengan uji Chi-Square menunjukkan tidak ada hubungan yang signifikan antara peran tenaga kesehatan dengan kepatuhan berobat, nilai probabilitas $(\mathrm{p})=0,880>0,050$.

Peran serta dukungan petugas kesehatan sangatlah besar bagi penderita, dimana petugas kesehatan adalah pengelola penderita dan petugas adalah yang paling sering berinteraksi, sehingga pemahaman terhadap konsisi fisik maupun psikis menjadi lebih baik dan dapat mempengaruhi rasa percaya dan menerima kehadiran petugas kesehatan dapat ditumbuhkan dalam diri penderita dengan baik. $^{13}$

\section{Variabel Yang Dominan Berpengaruh Terhadap Kepatuhan Berobat}

Analisis multivariat dilakukan dengan menggunakan uji regresi logistik. Tahap sebelum dilakukan uji regresi logistic adalah menentukan variabel bebas yang mempunyai $\mathrm{p}>0,25$ dalam uji hubungan dengan variabel terikat (dilakukan dengan uji Chi square test). Variabel yang dimasukkan dalam model prediksi regresi logistic berganda adalah variabel dengan $\mathrm{p}<0,05$ pada hasil uji Chi Square yaitu (pengetahuan, motivasi berobat dan dukungan keluarga). Variabel yang terpilih dalam model akhir regresi logistik dapat diketahui bahwa variabel dukungan keluarga akan dikeluarkan dari model karena memiliki nilai $\mathrm{p}>0,25$. Oleh karena itu variabel yang masuk dalam kandidat selanjutnya adalah variabel pengetahuan dan motivasi berobat.

Hasil setelah uji dan diseleksi menunjukkan bahwa variabel motivasi berobat akan dikeluarkan dari model karena memiliki nilai $\mathrm{p}>0,25$. Oleh karena itu variabel yang masuk dalam kandidat selanjutnya adalah variabel pengetahuan.Variabel pengetahuan ini merupakan variabel yang dominan berhubungan dengan kepatuhan berobat jalan. Dengan hasil $\mathrm{OR}=0,330$, yang berarti bahwa pengetahuan yang baik penderita DM Tipe II mengenai Diabetes Mellitus akan meningkatkan kepatuhan berobat jalan pasien sebanyak 0,33 kali lebih besar dibandingkan dengan pasien yang kurang memiliki pengetahuan tentang diabetes mellitus.

Pada penderita yang mempunyai pengetahuan yang lebih luas memungkinkan pasien itu dapat mengontrol dirinya dalam mengatasi masalah yang dihadapi, mempunyai rasa percaya diri yang tinggi, berpengalaman, dan mempunyai perkiraan yang tepat bagaimana mengatasi kejadian serta mudah mengerti tentang apa yang dianjurkan oleh petugas kesehatan, akan dapat mengurangi kcemasan sehingga dapat membantu individu tersebut dalam membuat keputusan, Pengetahuan atau kognitif merupakan domain yang sangat penting untuk terbentuknya suatu tindakan prilaku yang didasari pengetahuan alan lebih langgeng daripada yang tidak didasari pengetahuan. Pengetahuan merupakan domain dari perilaku yang sangat penting untuk terbentuknya tindakan seseorang. ${ }^{10}$

\section{Kesimpulan}

Berdasarkan hasil penelitian dan pembahasan dapat diambil kesimpulan bahwa pengetahuan, motivasi berobat, dukungan keluarga, dengan kepatuhan berobat jalan pasien DM Tipe II di RSU Kabanjahe dengan kepatuhan berobat jalan pasien DM Tipe II di RSU Kabanjahe 
tahun 2017, namun status pekerjaan, lama menderita, keikutsertaan asuransi kesehatan, keterjangkauan akses pelayanan kesehatan dan peran tenaga kesehatan tidak berhubungandengan kepatuhan berobat jalan pasien DM Tipe II di RSU Kabanjahe tahun 2017. Dan variabel pengetahuan merupakan faktor dominan yang berhubungan dengan kepatuhan berobat jalan pasien DM Tipe II di RSU Kabanjahe tahun 2017.

\section{Saran}

Hendaknya bagi RSU Kabanjahe dalam hal ini tenaga kesehatan untuk menyediakan sarana fasilitas berupa media yang berisi informasi, dan edukasi mengenai cara-cara pencegahan serta pengobatan DM Tipe IIdiruang pemeriksaan agar dapat menambah pengetahuan masyarakat dan penderita DM Tipe II mengenai penyakit DM Tipe II serta melakukan pendataan ulang atau memantau pasien yang datang untuk kontrol maupun yang datang untuk berobat.

\section{Daftar Pustaka}

1. International Diabetes Federation. Diabetes Atlas Sixth Edition, International Diabetes Federation 2013, http://www.idf/sites/default/files/EN_6E_Atlas_ Full_0.pdf, diakses tanggal 4 Januari 2014.

2. WHO. World Health Statistics. WHO Press. Geneva; 2002.
3. Ramachandran A, Snehalatha C, Shetty AS \& Naditha A. Trends is Prevalence of Diabetes in Asian Countries. World Jurnal of Diabetes. 2012. Vol. 3, Issue 6. India. Diakses 27 Oktober 2015 dari http://www.ncbi.nlm.nih.gov/pmc/articles/PMC 3382707/

4. Riskesdas. Laporan Riset Kesehatan Dasar 2013 Badan Penelitian dan Pengembangan Kesehatan Kementrian Kesehatan RI. Jakarta: Kemenkes RI; 2013.

5. Sinaga M. Karakteristik Penderita Diabetes Mellitus dengan Komplikasi yang Dirawat Inap di Rumah Sakit Vita Insani Pematangsiantar Tahun 2011. Skripsi Mahasiswa FKM USU, Medan.

6. Kemenkes RI. Profil Kesehatan Indonesia. Jakarta : Kementerian Kesehatan Republik Indonesia; 2014.

7. Suhadi. Diabetes Mellitus Pria. Surabaya: Airlangga University Press; 1996.

8. Ketut Gama et al, Faktor - factor Penyebab Ketidakpastian Kontrol Penderita Hipertensi, Jurnal Keperawatan; 2014.

9. Notoatmodjo, S. 2010. Ilmu Perilaku Kesehatan. Jakarta: Rineka Cipta.

10. Notoatmodjo S.Ilmu Kesehatan Masyarakat (Prinsip-Prinsip Dasar). Jakarta: Rineka Cipta; 2008.

11. Notoatmodjo S. Metodologi Penelitian Kesehatan, Edisi Revisi Cetakan 1, Jakarta: PT Rineka Cipta; 2003.

12. Niven N. Psikologi Kesehatan. Jakarta: ECG; 2002.

13. Novian A. Faktor Yang Berhubungan Dengan Kepatuhan Diit Pasien Hipertensi (Studi Pada Pasien Rawat Jalan Di Rumah Sakit Islam Sultan.Tesis. Pascasarjana, Universitas Hasanuddin. Makassar; 2013. 